\title{
The Curriculum Project on Professional and Pedagogical Teachers' Communication Culture Formation
}

\author{
Albina R. Shaidullina \\ Almetyevsk State Oil Institute, 423450, Almetyevsk, Russia \\ Email: albina-plus@mail.ru \\ Natalya Y. Evsyukova \\ Vitaly A. Mikhailov \\ Chuvash State Pedagogical University named after I.Y. Yakovlev, 428032, Cheboksary, Russia \\ Farida S. Gazizova \\ Alfiya R. Masalimova \\ Kazan (Volga region) Federal University, 420008, Kazan, Russia \\ Elmira R. Khairullina \\ Ilkhamiya I. Galimzyanova \\ Kazan National Research Technological University, 420015, Kazan, Russia
}

\section{Doi:10.5901/mjss.2015.v6n2s3p202}

\section{Abstract}

The changes in the socio-economic and spiritual spheres of modern society, trends in the renewal of the educational process put forward new demands to the level of modern teachers professional and pedagogical communication culture formation. The solution to this problem objectively requires the development of more flexible curricula of professional growth, aimed at the efficient formation of their professional and pedagogical communication culture. In this regard, this article presents the project of the curriculum "Fundamentals of professional and pedagogical communication culture formation", which allowed reveal its effectiveness for teachers who has two years of experience of professional activity. The materials of the articles are of theoretical and practical value for teachers of secondary schools, and for teachers - beginners of high schools and colleges of vocational education.

Keywords: professional and pedagogical communication culture, the teacher, the content of the curriculum.

\section{Introduction}

\subsection{The urgency of the problem}

For a long time in psychological and pedagogical literature, the communication culture was understood as a technique of communication, and the main emphasis was given to the development of rhetoric, pantomimic, verbal and non-verbal means of communication, models, styles, and so on (Makarova, 2000; Galaguzova, 2001). This phenomenon may be explained by the fact that the existing curricula of teachers professional training on psychology, pedagogy, methodology contain virtually no information either about the features of their professional and pedagogical communication culture, nor the methods of identification of development levels, neither of strategies and models for its development and improvement in the continuous process of professional activity. 


\subsection{Problems of teachers in their professional activities}

Psycho-pedagogical studies and our own observations suggest that untrained teachers are not able to effectively improve of their professional and pedagogical communication culture, because they do not know its characteristics; often use only a quantitative increase in knowledge gained in lectures and not a qualitative change, purchased in practice-oriented training; there is lack of understanding and ignorance of the problems associated with the development and improvement of professional and pedagogical communication culture (Logacheskaya, 1990; Abrosimova, 1998). Significant problems of teachers in professional activity are disclosed by V.I.Baydenko (2003), N.A.Astashova (2001), E.V.Bondarevskaya (1999), V.P.Bespal'ko (1998), Z.I.Ravkin (2000), N.E.Vorob'ev (1992), M.I.Bolotin (2002), G.I.Minskaya (1998), V.V.Kuznetsov (1999), I. A.Zimnyaya (2003) L.G.Korchagina (2007).

The most important components of pedagogical mastery are displayed in the works by N.V.Bordovskaya (2001), L.Gohberg (2002), M.M.Potashnik (2010).

Features and development of pedagogical mastery of future teachers are studied by such scholars as: K.E.Romanova (2010), E.S.Golovina (2005), L.V.Zanina (1994). Therefore, the relevance of the problem suggests the need to develop more flexible curricula of teachers' professional growth, aimed at the efficient formation of their professional and pedagogical communication culture.

\section{Materials and Methods}

\subsection{The objectives of the curriculum}

The proposed curriculum "Fundamentals of formation of professional and pedagogical communication culture" implies a comprehensive and consistent work of psychologists, teachers and teachers in the process of entity interaction in the training groups, which identify deficiencies in the development levels of their professional and pedagogical communication culture, provide to evaluation and critical reflection.

The aim of the curriculum is to increase the level of formation of teachers' professional and pedagogical communication culture via the manifestation of the following important professional skills: (a) the development of the components' optimal combination of teachers' professional and pedagogical communication culture (communication and organizational skills, empathy, self-control in communication, group of professionally significant personal qualities of the teacher); b) the effective use of these components in professional activities when building a process of communication; $c$ ) critical analysis of the generated level of professional and pedagogical communication culture and constructive definition of new means to their further improvement.

\subsection{Requirements to the curriculum}

The program consists of three parts of requirements for its content:

1. Considering as the primary material of the basic philosophical, psychological and pedagogical concepts (culture, culture of communication, professional and pedagogical culture, formation, development, formation, and so on);

2. The implementation of an interdisciplinary approach to the development of the main methodological problems' solvingvia the integration of disciplines and by establishing relationships, meaningful interdependencies;

3. The work organization on the basis of educational activity forms diversity in the study course: frontal, group, individual, differentially-group.

\subsection{The stages of the curriculum}

On the ground, anamnestic stage of the curriculum implementation (monitoring stage, which collects information about the activity entity), information about the professional achievements of teachers is collected, which are determined by high level of development of their professional and pedagogical communication culture.

Second, the diagnostic stage is associated with the individual assessment of formation level of professional and pedagogical communication culture based on the study of the capabilities and peculiarities of teachers, held in conjunction with the psychologist.

At the third stage of work with teachers a major role belongs to teachers, whose task is to generate a higher level of professional and pedagogical communication culture. These requirements are implementedvia a wide range of 
pedagogical techniques and methods (the author curricula, individual counseling, training in educational institutions of professional education).

\subsection{Content part of the training curriculum}

The procedural component suggests the involvement of teachers in independent cognitive and creative work for the study and development of those or other problems, creating opportunities for them to apply knowledge in practice in real conditions of a secondary school.

The teacher was always interested in the ways, methods that would help him to increase his formation as an entity of activity and communication. An important place is assigned to the socio-psychological training (Makarova, 2000; Kuznetsov, 1999). The necessity of introducing the training curriculum is dictated by the fact that the diagnosis or monitoring of the formation and development of professional and pedagogical communication culture belongs to the most important elements of thecurriculum. Therefore, this part of the curriculum is called as a "curriculum - training".

Training curriculum emphasizes the idea of the formation and development of the components of teachers' professional and pedagogical communication culture, and the need to identify all the individual qualities that constitute the internal conditions of the further development of this phenomenon (Romanova, 2010; Zimnyaya, 2004).

The training curriculum includes theoretical and practical parts. The theoretical course outlines psychological and pedagogical components of teachers' professional and pedagogical communication culture formation, the ways of its improvement. Actually the methodological part includes instructions and exercises on the application of individual techniques, games, organization, training classes, courses, etc.

The training curriculum consists of four sections: General questions of professional and pedagogical communication culture"(6 hours), "Diagnosis of formation of teachers' professional and pedagogical communication culture structural components" (12 h.), "The formation of psycho-pedagogical components of teachers' professional and pedagogical communication culture"(8 hours), "The development of teachers' professional and pedagogical communication culture in the first five years of professional activity" (10 hours).

The content of the above enumerated general issues considers different theoretical approaches. In the second section, the proposed methods of diagnosis are based on the concept about the structure of teachers' professional and pedagogical communication culture. Practical exercises include the development of diagnostic techniques, making of some tasks of development curriculum, testing, preparation and discussion of reports.

The curriculum provides:

- the necessity to support the teachers' needs in further professional and pedagogical communication culture level formation improvement.

- ensuring the depth and richness of the curriculum's content.

The content of educational curricula includes: problem solving, aimed at raising the level of teachers' professional and pedagogical communication culture on the basis of the project development; organization of discussions, brainstorming, criteria providing for teachers' professional and pedagogical communication culture levels' development; publications of teachers in scientific journals; the implementation of a "living" professional activities for professional and pedagogical communication culture.

The developed program-training is not the only guidance on the formation of professional and pedagogical culture of the teacher. This curriculum is based on experimental data and tested on a representative sample of teachers. In it, as in any psychological training, there is need to exercise caution in interpreting the results, because the data obtained are not always clear: too many factors affect the results of the training, and they are cannot be eliminated. They include entity past experience; information that entities receive regardless of the training; the impact of professionally significant personal qualities of the teacher, etc. In addition, a collective creative process is often hidden from view and it is necessary to judge on circumstantial evidence.

Scope of training curriculum- 36 hours. It is focused on development of communicative and organizational skills, empathy, self-control in communication, professionally significant personal qualities of a teacher.

Each training session begins with warm-up exercises. If one exercise is not possible for a single lesson, it is continued on the following. During the training it is necessary to keep the following principles in group work: continuous participation in the work of the group; the closeness of the group; the activity of each participant of the training; strict keeping of the principle "here and now"; the confidentiality of information. 


\subsection{The technological component of the training curriculum}

Training of communication traditionally begins with exercises designed to develop skills of friendly welcome.

Exercise 1- "non-traditional greeting", it is aimed at communicative and organizational skills formation. The moderator says: "We are used to the stereotypes. They help us to live, but sometimes impoverish our lives. Let's try to experience new emotions and at the same time develop non-traditional greeting. Maybe someone will offer his own version. We are ready to try."

This is followed by activities aimed at the formation of the self- control in communication, empathy, professionally significant personal qualities of a teacher, which are used as stress relief skills, non-verbal communication development.

Exercise 2 - "Namecard", it is aimed at self-control formation in communication. All participants and coach sit by persons inside the circle. The coach explains the rules and first begins the exercise. Each participant in turn goes in the center of the circle and calls his name, accompanying it with a gesture or a pose. The choice of gesture or posture arbitrary and occurs according the player's wish. The idea is that through this movement was transferred his image. For example, in the center of the circle is one of the participants and calls his name "Anna", illustrating the low Russian bow. Another participant takes the name "Irene" and makes the squat. Using these gestures participators demonstrate themselves, their character, temperament, their "name card". After participant's presenting the group his name, all members of the group talk how they understood their partners in the game. Especially the cases are analyzed in which the person's name does not match the pose, "through which he introduced himself.

After this lesson, comes exerciseaimed at as a stress relief, so mastering the skills of public speaking, development of creative abilities and a number of professionally significant personal qualities of a teacher.

Moderator suggests to discuss the forms of addressing, and to pass the test HAM (health, activity, mood). Using this technique, you can obtain information about the status of participants in extreme conditions.

Exercise 3 - "Secret word". One participant thinks of a word, which he keeps in secret, but tells the first letter. Let us assume that the letter "K". Some of the participants ask a question, for example: "Is this an animal?" or "Is it a part of a word?" Other participants, including one who thought of a word, quickly guess a word that would start on the letter, and which belongs to the class of the objects specified in the question. If the participant who thought of the word is the first who know such word he names the word and the game continues so someone asks new question. If someone says the word that answers the question and starting with the appropriate letter before the participant, conceived the word, the participantannounces the second letter of his word. Again some of the participants ask a question, and all the rest think of a word beginning with two letters that are declared by the participant. The exercise continues until the word is guessed.

Exercise 4 - "Ship". All participants together with the coach are sailing on the ship. The ship sails along the coast, Islands, octopus, the night comes, day comes again, and storm comes. Each participant in turn tells where the ship floats, what is visible around what is happening on the ship, and so on. So they sail some time (about 15-20 turns), and then the coach commands to turn to 180 degrees, and the participants have to repeat all the way to the port of departure, but in reverse order.

Exercise 5 - "Intellectual tournament battle", it is aimed at the formation of empathic listening. All participants are divided into three teams. Each team is offeredthe task according their choice. Teams should not know the conditions of the tasks requested to the other team. The preparation time to answer the questions is 15 minutes. After that time the participants have to answer the questions. All the participants listen to the answer, and then the members of the other teams ask two questions on the same topic to the team that was asked. When all teams will play the procedure of the answers' evaluation starts. The rating ranges from 1 (unsatisfactory) to 5 (comprehensive response). As the answers to the main question are estimated sothe answers to the additional questions are estimated. Assessment of the work of each team is the sum of the estimates of the responses of the participants. Usually that teamwins which will score the most points.

Exercise 6 - "Magnet", is aimed at the development of self-control in communication. All the participants stand in crowd in the corner of the training room. One participant is invited and he is told that he is the biological magnet. All other participants imagine as if they stuck tohoney wall. The "magnet" closes his eyes, straining and beginning mentally pulling someone out of jelly. He who feels, that he is pulled by him, go out from the adhesive mass with speed and with a characteristic sound comes out of jelly and stick to the "magnet". Then they together again close their eyes and begin mentally pull someone else, and so on until all participants will not be detached from the wall and will not stick to the "magnet".

Exercise 7 - "The suitcase of qualities", is aimed at the formation of professionally significant personal qualities of a teacher. Participants one by one come out of the room and the remaining collect him a "suitcase" in which he put those professionally important personal qualities of a teacher that help and hinder him in the development of professional and 
pedagogical communication culture. The main rule - put in "the suitcase" an equal number of positive and negative qualities; to specify the qualities that emerged during the sessions. Selected secretary captures on paper the specified qualities. The guy, who filled his "suitcase", can ask any question, if it is not clear that was written by the secretary. A "case" should be given to each participant.

Exercise 8 - "Step-2". The coach announces the end of the training, ask participants to leave the room in turn. The first participant takes a few steps toward the door, behind him the second, trying to copy all the movements of the first and adding to them his own detail. This is followed by the third, copying all movements of the second and adding his detail, and so on, the last comes out the coach, repeating the movement of all participants (limping on both legs, tugging at the neck, bouncing on every third invoice, etc).

Exercise 9 - "Artist 2", aimed at the formation of pedagogical tact. Ask the participants to sit comfortably, close their eyes and mentally to see the forest, as the dark wall rising to the lake, on the shores of which stands the hotel where the training is conducted, to hear the cry of the seagulls and feel the cool evening breeze. Then mentally to identify himself with one of the characters of the picture, with one of the elements of the picture, to feel himself in his place, and at the moment when he manages to do it, to get up and leave the room, telling everyone with whom heidentified himself (for example: "I am a cloud, I float away beyond the horizon", "I'm Lily, I folded the petals and plunged into the water with the sunset', and so on). Other participants must imaginethe picture without this element.

Training exercises should be applied correctly, "dosed" taking into account the individual characteristics and abilities of the participants. Otherwise, you can only achieve the full effect of "maturity" of personal growth.

\section{Results}

This curriculum was carried out among teachers with experience of 2, 4, 5 years of professional activity.

After training as part of the proposed project in the control and experimental groups were conducted slices for the control experiment, the results of which are presented in table 1.

Table 1. The results of the experiment on the study of levels development of teachers' professional and pedagogical communication culture

\begin{tabular}{|c|c|c|c|c|c|c|c|}
\hline \multirow{2}{*}{ Experience } & \multirow{3}{*}{ Groups } & \multicolumn{3}{|c|}{ The levels development of teachers' professional and pedagogical communication culture } \\
\cline { 3 - 8 } & & \multicolumn{3}{|c|}{ before the experiment } & \multicolumn{3}{c|}{ After the experiment } \\
\cline { 3 - 8 } & & $\mathrm{H}$ & $\mathrm{A}$ & $\mathrm{L}$ & $\mathrm{H}$ & $\mathrm{A}$ & $\mathrm{L}$ \\
\hline \multirow{2}{*}{2 years } & $\mathrm{C}$ & $18 \%$ & $65 \%$ & $17 \%$ & $22 \%$ & $70 \%$ & $8 \%$ \\
\cline { 2 - 8 } & $\mathrm{E}$ & $21 \%$ & $71 \%$ & $8 \%$ & $45 \%$ & $53 \%$ & $2 \%$ \\
\hline \multirow{2}{*}{4 years } & $\mathrm{C}$ & $42 \%$ & $53 \%$ & $5 \%$ & $44 \%$ & $54 \%$ & $2 \%$ \\
\cline { 2 - 8 } & $\mathrm{E}$ & $40 \%$ & $48 \%$ & $12 \%$ & $71 \%$ & $27 \%$ & $2 \%$ \\
\hline \multirow{2}{*}{5 years } & $\mathrm{C}$ & $52 \%$ & $48 \%$ & & $48 \%$ & $52 \%$ & $21 \%$ \\
\cline { 2 - 8 } & $\mathrm{E}$ & $45 \%$ & $47 \%$ & $8 \%$ & $76 \%$ & $21 \%$ \\
\hline
\end{tabular}

From table 1 it is evident that in the control group - 18\% of the teachers (2 years of experience) has the formation of professional and pedagogical communication culture at a high level, whereas at average - 65\%,at low - 17\%. In the control group the development of teachers' professional and pedagogical communication culture occurred in daily teaching activities. So after the experiment here at a high level was $22 \%$ of teachers, at average - $70 \%$, at low - $8 \%$. In accordance with the ratio $\times 2$ the obtained value is greater than the corresponding table value (degrees of freedom 2), if the probability of acceptable error less than 0.05 .

In the experimental group teachers with experience of two years the following results are obtained: a high level before the experiment belonged to $21 \%$, the average to $71 \%$, low - $8 \%$. After the experiment it was: $45 \%, 53 \%$ and $2 \%$. According to the results of the 2xthe statistical significance is revealed $(P<0,001)$, indicating the impact of the experiment in this group of teachers.

Before the experiment in the control group teachers with experience of 4 years high levels were observed among $42 \%$ of the teachers, after the experiment it was $44 \% .53 \%$ of the teachers before the experiment had the average level, then the average level belonged to $54 \%$. Accordingly, before the experiment - $5 \%$ of the teachers had low level, after the experiment - $2 \%$. Significant changes in the levels of development of teachers' professional and pedagogical communication culture of this group did not occurred.

In the experimental group the results were the following : high level typical for $40 \%$ and $71 \%$; average for $48 \%$ and 
$27 \%$; low for $12 \%$ and $2 \%$. The ratio $\times 2$ shows that it is higher than the tabular index, which indicates a statistically significant change in the forming experiment.

Among the teachers with experience of 5 years professional activity in the control group before the experiment it was $52 \%$ and after - $48 \%$ at a high level, and the average level of development belonged to $48 \%$ and after - $52 \%$. The changes did not increase, but decrease. In the control group, high level belonged to $45 \%$ and after it to $76 \%$, average $47 \%$ and $21 \%$, low - $8 \%$ and $3 \%$. Changes at the significance level are of $95 \%$.

The results of statistical analysis indicate that formative experiment proceeds most effectively in the experimental group of teachers with 2 years' experience at a significance level of $99,99 \%$.

\section{Discussions}

Experimentally proved, that the formation of teachers' professional and pedagogical communication culture is a dynamic process of the development of their communicative and organizational skills, self-control in communication, empathy, professionally significant personal qualities in the entity pedagogical interaction between teacher and student.

In the control and experimental groups of teachers with experience of 2 years before the curriculum implementation the difference in the increase (in \% ratio) of levels development of professional and pedagogical communication culturewas not observed. After the implementation of the curriculum in the experimental group in comparison with the control group, significant changes occurred related to the increase in the number of teachers having a high level of formation of professional and pedagogical communication culture. This age is a sensitive and more favorable for the formation of professional and pedagogical communication culture of the teacher.

\section{Conclusion}

The implementation of the curriculum "Basics for the formation of professional and pedagogical communication culture" promotes to successful generation of it among teachers with experience of two years. In the control group also the natural development and improvement in the process of pedagogical activity is observed, which indicates the phenomenal world of professional and pedagogical communication culture of the teacher as a pedagogical phenomenon, which in its formation proceeds according to natural laws and requires not so much control from the outside, but much of the account of a psycho-pedagogical components of its formation and adjustment.

\section{Referenses}

Abrosimova, Z. F. (1998). Pedagogical culture teacher. Science and Education Zauralye: 2 (3), 18-20.

Astashova, N. A. (2001). Axiological modern teacher education: methodology, concepts, models and technology development. Bryansk., 27.

Baydenko, V. I. (2003). Modernization of vocational education: the current stage of the text. Moscow: Research Center of quality problems of training specialists, 674 .

Bespal'ko, V. P. (1989). Pedagogy and advanced learning technologies. Moscow: Pedagogy, 192.

Bolotin, M. I., \& Dzhamaludinov, G. (2002). Social problems of the teaching staff. Higher education in Russia: 4, 21.-32.

Bondarevskaya, E. V. \& Kulnevich, S. V. (1999). Pedagogy: personality in humanistic theories and systems of education. Moscow: Rostov, 560.

Bondarevskaya, E. V. (1999). Pedagogical culture as a social and personal values. Pedagogy: 3, 37-43.

Bordovskaya, N. V. (2001). Dialectics of pedagogical research: logical and methodological problems. St.Petesburg, 512.

Galaguzova, Y. N., Sorvacheva, G. V., \& Shtinova, G. N. (2001). Social pedagogy: Practice eyes of teachers and students. Moscow: Vlados, 224.

Gokhberg, L. (2002). Personnel potential of Russian science. Higher education in Russia: 4, 8-21.

Golovina, E. S. (2005). Teacher promote a professional culture of the future social teachers in high school (Unpublished master's thesis). Ekaterinburg, 189.

Korchagina, L. G. (2007). Reflective-pictorial problems as means of formation of pedagogical culture of the teacher (Unpublished master's thesis). Tyumen, 192.

Kuznetsov, V. V. (1996). Pedagogical culture. Professional: 5, 21-22.

Kuznetsov, V. V. (1999). Development of pedagogical culture trainers. Ekaterinburg: Publishing House of the Urals. state. prof.-ped. University Press, 291.

Logacheskaya, S. P. (1990). Reach every student. Kiev: Radyans'ka School.

Makarova, L. N. (2000). Teachers in higher education: individual, style, activity. Moscow: Tambov.

Maksakova, V. I. (2001). Pedagogical Anthropology. Moscow: Publishing Center "Academy", 208. 
Minskaya, G. I. (1998). Formation of components of pedagogical activity in the course of research students. Tula: Toole. state. ped. Inst. them. Leo Tolstoy, 200-203.

Potashnik, M. M., \& Vul'fov, B.Z. (1983). Pedagogical situations. Moscow: Pedagogy, 144.

Ravkin, Z. I. (2000). Problems of education in the context of a humanistic paradigm of the XIX century. Moscow, 216.

Romanova, K. E. (2010). Conceptual bases of formation and development of pedagogical skills of future teachers. Volga scientific journal: 2, 132-135.

Romanova, K. E. (2010). Features of concept formation and development of pedagogical skills of future teachers. Science and school: 2 , 63-66.

Vorob'yev, N. E., Suhantseva, V.K., \& Ivanov, T. (1992). About pedagogical culture of the future teacher. Pedagoy: 1-2, 66-70.

Zanina, L. V. (1994). Formation of humane pedagogical position of the future teacher in a multilevel system of higher pedagogical education (Unpublished master's thesis). Rostov-on-Don, 199.

Zimnyaya, I. A. (2003). Key competencies - a new paradigm of education result text. Higher education: 5.

Zimnyaya, I. A. (2004). Key competencies as effectively-targeted competency-based approach to education. Moscow: Research Center challenges the quality of training, 40 . 